\title{
Molecular and Phenotypical Characterization of Mannheimia haemolytica Isolated from Goats in Baghdad Province
}

\author{
Waffa A. Ahmed1', Roua J. Mohammed1', Ilham A. Khalaf ${ }^{2}$ \\ ${ }^{1}$ Department of Microbiology, College of Veterinary Medicine, Baghdad University, Baghdad, Iraq \\ ${ }^{2}$ Al-Razi Center for Research and Diagnostic Kits, Ministry of Industry and Minerals, Baghdad, Iraq \\ Email: waffaabduleah@yahoo.com
}

How to cite this paper: Ahmed, W.A., Mohammed, R.J. and Khalaf, I.A. (2017) Molecular and Phenotypical Characterization of Mannheimia haemolytica Isolated from Goats in Baghdad Province. Advances in Microbiology, 7, 304-314.

https://doi.org/10.4236/aim.2017.74025

Received: March 20, 2017

Accepted: April 25, 2017

Published: April 30, 2017

Copyright (c) 2017 by authors and Scientific Research Publishing Inc. This work is licensed under the Creative Commons Attribution International License (CC BY 4.0).

http://creativecommons.org/licenses/by/4.0/

\begin{abstract}
Mannheimia haemolytica (M. haemolytica) is a gram negative bacterium which can infect humans and animals. It's commensal as a normal flora of the nasopharynx and tonsils in cattle, sheep and goats, pneumonic pasteurellosis is one of the most economically important infectious disease in goats worldwide prevalence. This study aimed to investigate the incidence of $M$. haemolytica by bacteriological and molecular characterization in goats. One hundred nasopharyngeal swabs were collected from apparently healthy field goats, seven lung tissue specimens and five nasal mucus swabs from slaughtered goats in Baghdad. All samples were cultured on Blood and MacConky agars. Biochemical tests and EPI20E kit were used for identification of the suspected colonies. 5 (4.46\%) isolates of $M$. haemolytica were identified phenotypicaly and confirmed diagnosis by polymerase chain reaction (PCR) technique using two primers 16s rRNA and 12s rRNA genes.The results of this study concluded that identification of $M$. haemolytica by PCR was in accordance with those of phenotypic tests and it providing the basis for effective preventative strategies through epidemiological studies performance.
\end{abstract}

\section{Keywords}

Mannhimia haemolytica, Goats, Polymerase Chain Reaction (PCR), Baghdad

\section{Introduction}

Pneumonic pasteurellosis is one of the important respiratory diseases of cattle, sheep and goats worldwide distribution, It is usually caused by Mannheimia haemolytica biotype A [1]. It's considered a zoonotic disease, causes bronchiectasis, bronchitis, pneumonia, urinary tract infection, brain abscess, septicemia in 
an infant [2] [3] [4] [5]. M. haemolytica is an opportunistic pathogen that has been detected residing in the respiratory tract of healthy and sick ruminants and capable of causing infection in cases of compromised body defense by a variety of stress factors such as transportation, malnutrition, adverse physical, environmental or climatic conditions, previous or co-infection with certain respiratory viruses, mycoplasma or other types of bacteria [6]. Methods for its proper and rapid identification are critical to treating infected animals or gathering epidemiological data. Phenotypic tests have been described in details for identification of $M$. haemolytica and other species grouped within the genus Mannheimia, however, these test consist from 12 biochemical test and can be costly, time consuming and not specific for identification of M. haemolytica [7].

Few studies dealing with $M$. haemolytica infections were carried in Iraq, the bacteriological and serological methods were mostly performed for identification M. haemolytica. However, number of reports described prevalence of $M$. haemolytica in field animal by these methods only. The respiratory infection with M. haemolytica occurred in Iraq during the winters months, in (14\%) and (4\%) from infected and healthy sheep respectively [8]. In other reports, were reported M. haemolytica was isolated from sheep in Baghdad in (8.57\%), whereas, $M$. haemolytica A serotype was isolate in (21.22\%), while T serotype was isolated in (78.78\%) [9]. Subsequently, the increase in the age of lambs accompanied by increase serotype $\mathrm{T}$ and decreases in serotype A [10]. As well as $M$. haemolytica isolated during an outbreak in mountain goat, deer and gazalles, the prevalence rate of the pathogen from nasopharyngeal swabs and blood samples was (68.0\%) and $(3.17 \%)$ respectively, while the prevalence rate of serotype A was (48\%) and serotype $\mathrm{T}$ was (16\%) [11].

Molecular methods of bacterial identification have proved beneficial to overcoming some limitations of the conventional biochemical and serological methods and improved sensitivity and rapidity [12] [13], Species-specific PCR assays are available for some bacteria within the family Pasteurellaceae [14], and the polymerase chain reaction was found useful, specific and time saving for identification of $M$. haemolytica using different oligonucleotide primers [15]. Improved $M$. haemolytica detection by PCR, two amplicons based PCR assay were used, targeted $M$. haemolytica specific mitochondrial $16 \mathrm{~S}$ and $12 \mathrm{~S}$ ribosomal RNA (rRNA) gene [16] [17]. The study aimed to identified $M$. haemolytica from apparently healthy \& infected goats by phenotypic and molecular methods.

\section{Material and Method}

\subsection{Samples and Bacterial Isolation}

One hundred samples were collected from nasopharyngeal swabs of apparently healthy goats and twelve samples were taken from slaughtered goats (7 lung specimens and 5 nasal sinus mucus swabs). Then the samples were cultured in brain heart infusion broth (BHIB $\backslash$ Himedia, India) at $37^{\circ} \mathrm{C}$ for $24 \mathrm{hr}$, and inoculated on blood agar (B.AlHimedia, India) with 5\% sheep blood and MacConkey agar 
(M.A $\backslash$ Himedia, India), then incubated under anaerobic condition at $37^{\circ} \mathrm{C}$ for 24 $\mathrm{h}$ with $5 \% \mathrm{Co}_{2}$. Identification of the bacterial species was based on observation of their colonial morphology, Gram staining and biochemical characteristics (oxidase, catalase, indol, nitrate, urease, gelatin, simons citrate, motility, TSI, sugar fermentation tests) according to [18] [19]. The identification was confirmed by API20E kit. The API20E (Biomerieux Inc, USA) was done according to manufactures instructions.

\subsection{Standard Strain of M. haemolytica}

Standard strain of $M$. haemolytica (ATCC: P4WSO113) was supplied by Jovac Jordan Bio industries center. This strain was revived by adding $5 \mathrm{ml}$ of normal saline to lyophilized bacteria, and inoculated in broth and media which were incubated for $48 \mathrm{hr}$ at $37^{\circ} \mathrm{C}$ with $5 \% \mathrm{CO}_{2}$.

\subsection{Molecular Identification of M. haemolytica}

\subsubsection{DNA Extraction}

Bacterial cells (up to $1 \times 10^{9}$ ) were cultured, in BHI broth, and overnight incubated, then were transferred to $1.5 \mathrm{ml}$ micro centrifuge tube then centrifuged at $16,000 \mathrm{~g}$ for $1 \mathrm{~min}$, DNA was extracted using Presto Mini g DNA bacteria Kit according to manufacturer's instructions (Geneaid, KOBA). The extracted DNA was stored at $-20^{\circ} \mathrm{C}$ until use. The DNA concentration was measure by NANODROP-2000 spectrophotometer (Thermo Scientific Inc., USA).

\subsubsection{Primers}

Oligonucleotide primers for $M$. haemolytica were obtained from IDT (Integrated DNA Technologies/USA). The primer sequence of $M$. haemolytica 16SrDNA gene was (F-GCTAACTCCGTGCCAGCAG, R-CGTGGACTACCAG GGTATCTAATC) with size 304 bp [16] and the sequence of 12s rRNA gene was (F-TAACCCTTGTMCCTTTTGSATRRK, R-AGACTAACTTTTAAAGATACA GTGGG) with size 270 bp [17].

\subsubsection{PCR Amplification Analysis}

PCR amplification was performed on a final volume of $20 \mu$ containing 10 Intron-Master Mix (KOBA) which contains (Taq plymerase, PCR buffer, Gel loading buffer and dNTPs), $2 \mu \mathrm{l}$ (100 ng of DNA template) and $2 \mu \mathrm{l}$ of 10 pmol for each primer. The amplification of gene was carried out with Master cycler (Eppendrof, Germany). Amplified products were separated by agarose gel electrophoresis ( $1 \%$ agaros containing $0.5 \mathrm{mg}$ ethidium bromide in $0.5 \times$ Tris-EDTA electrophoresis buffer) at $90 \mathrm{~V} / 26 \mathrm{~mA}$ for $1 \mathrm{~h}$ and A $100 \mathrm{bp}$ DNA ladder (Bioneer, Korea) was used as a molecular size standard, Gel documentation system.

\section{Results}

Results of one hundred nasopharyngeal swabs of apparently healthy field goats $(0.00 \%)$ were negative for M. haemolytica (Table 1$)$. While, $3 / 7$ (42.85\%) isolates 
of M. haemolytica were isolated from the infected lungs tissue and 2/5 (40.0\%) nasal sinus mucus isolates from slaughtered goats (Table 1).

Identification of $M$. haemolytica was done by study colonial morphology on B.A and M.A and showed minor differences between field isolates and standard strain. Lung isolates appeared on B.A as small, gray and rough colonies. While nasal isolates appeared as large, gray and mucoid (smooth) colonies (Figure 1). Lung and nasal isolates showed beta haemolysis on the B.A after $24 \mathrm{~h}$. Lung isolates appeared as Pink pinpoint colonies on M.A, while nasal isolate appeared as mucoid pink colonies (Figure 2). While, standard strain of $M$. haemolytica appeared as small, gray and rough colonies on B.A haemolysis appeared after $48 \mathrm{~h}$ under neath the colony (Figure 1), and as dark pink pinpoint colonies on M.A (Figure 2). All isolates and standard strain were stained by Gram stain and methylene blue stain, the colonies appeared as G-, coccobacilli or short-rod singly or in pairs, clear bipolarity was appeared by methylene blue stain.

All isolates and standard strain examined by biochemical tests (Table 2). And EPI20E, minor differences were appeared between field isolates and standard strain.
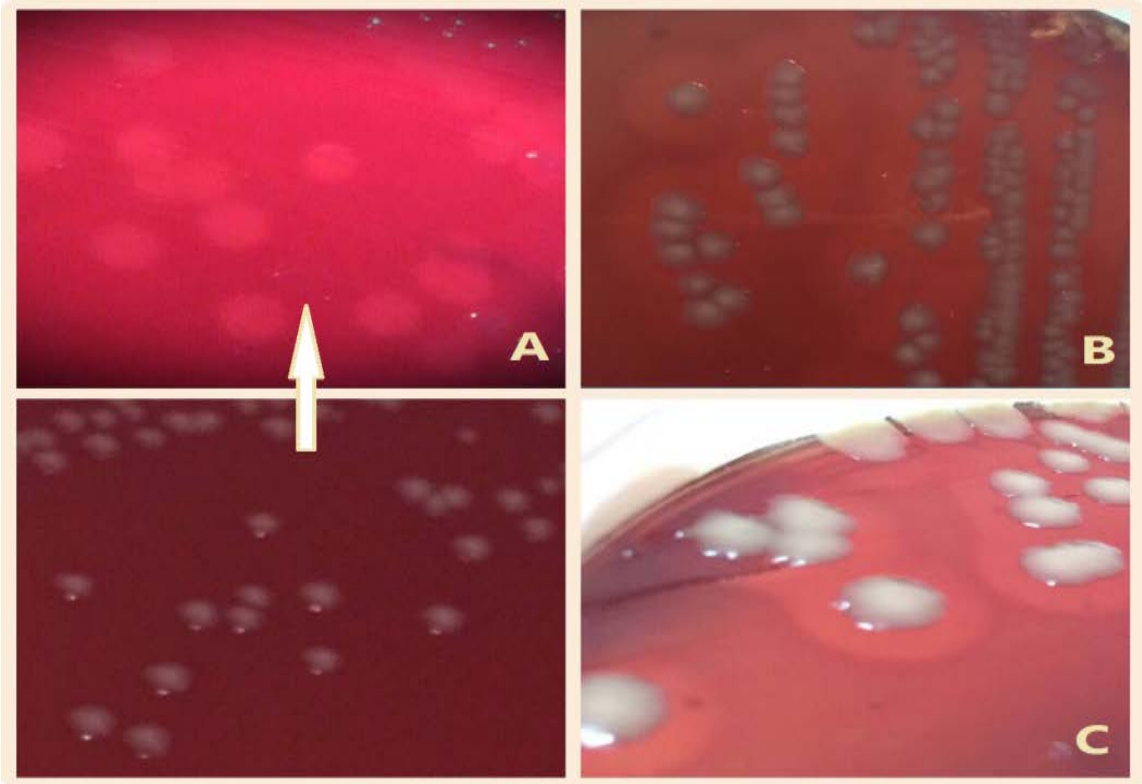

Figure 1. M. haemolytica colonies on B. A (A) Standard strain (B) and (C) Nasal\& Lung isolates respectively.

Table 1. Source and isolation rate of $M$ haemolytica from field and slaughtered goats.

\begin{tabular}{ccccc}
\hline Studies months & $\begin{array}{c}\text { Type and sources of } \\
\text { samples }\end{array}$ & $\begin{array}{c}\text { No. of examined } \\
\text { samples }\end{array}$ & No. of samples & $\begin{array}{c}\text { Positive } \\
\text { percentage \% }\end{array}$ \\
\hline $\begin{array}{c}\text { October 2015 to } \\
\text { February 2016 }\end{array}$ & $\begin{array}{c}\text { Field sample } \\
\text { (nasopharyngeal swabs) } \\
\text { Slaughter sample } \\
\text { (lungs tissue) }\end{array}$ & 100 & 0 & $00.00 \%$ \\
$\begin{array}{c}\text { March } \\
\text { to April }\end{array}$ & $\begin{array}{c}\text { Slaughter sample } \\
\text { (nasal mucus) }\end{array}$ & 5 & 3 & $42.85 \%$ \\
& Total & 112 & 2 & $40.00 \%$ \\
\hline
\end{tabular}



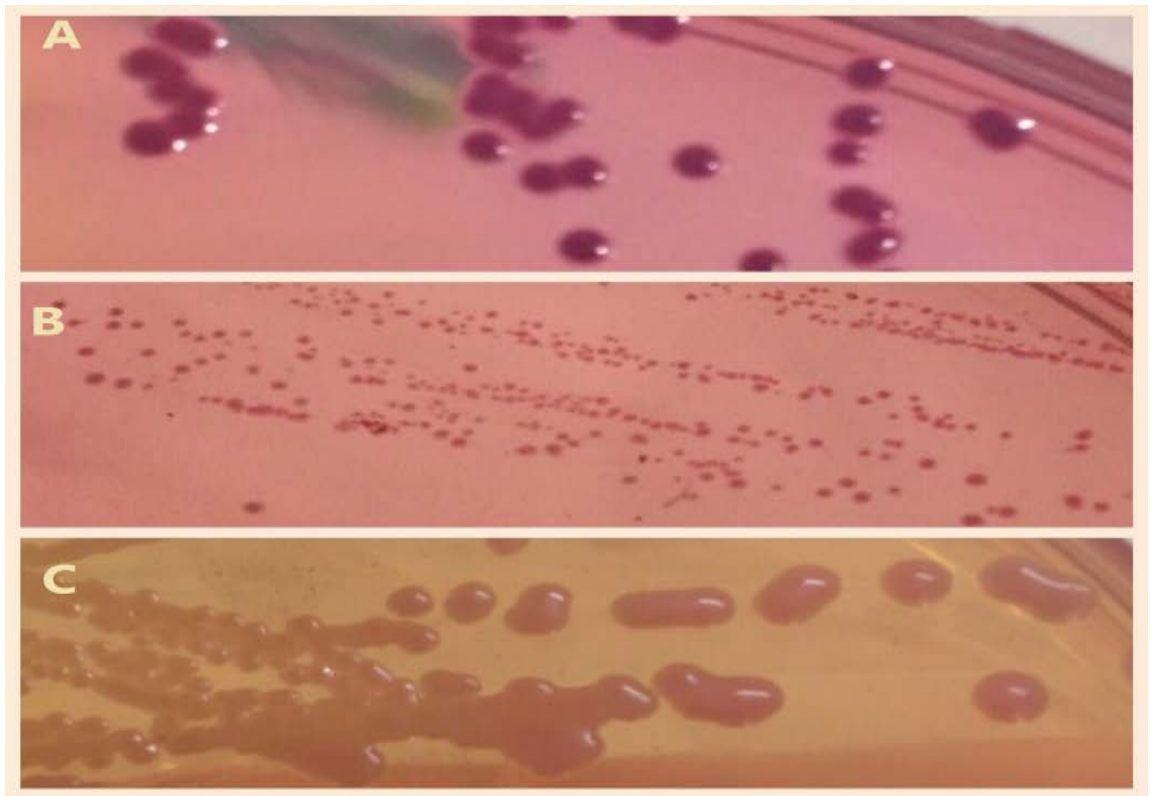

Figure 2. M. haemolytica colonies on M.A (A) Standard strain (B and C) Lung \& Nasal isolates respectively.

Table 2. Comparison between recovered isolates and standard strain of M. haemolytica in Phenotypic test.

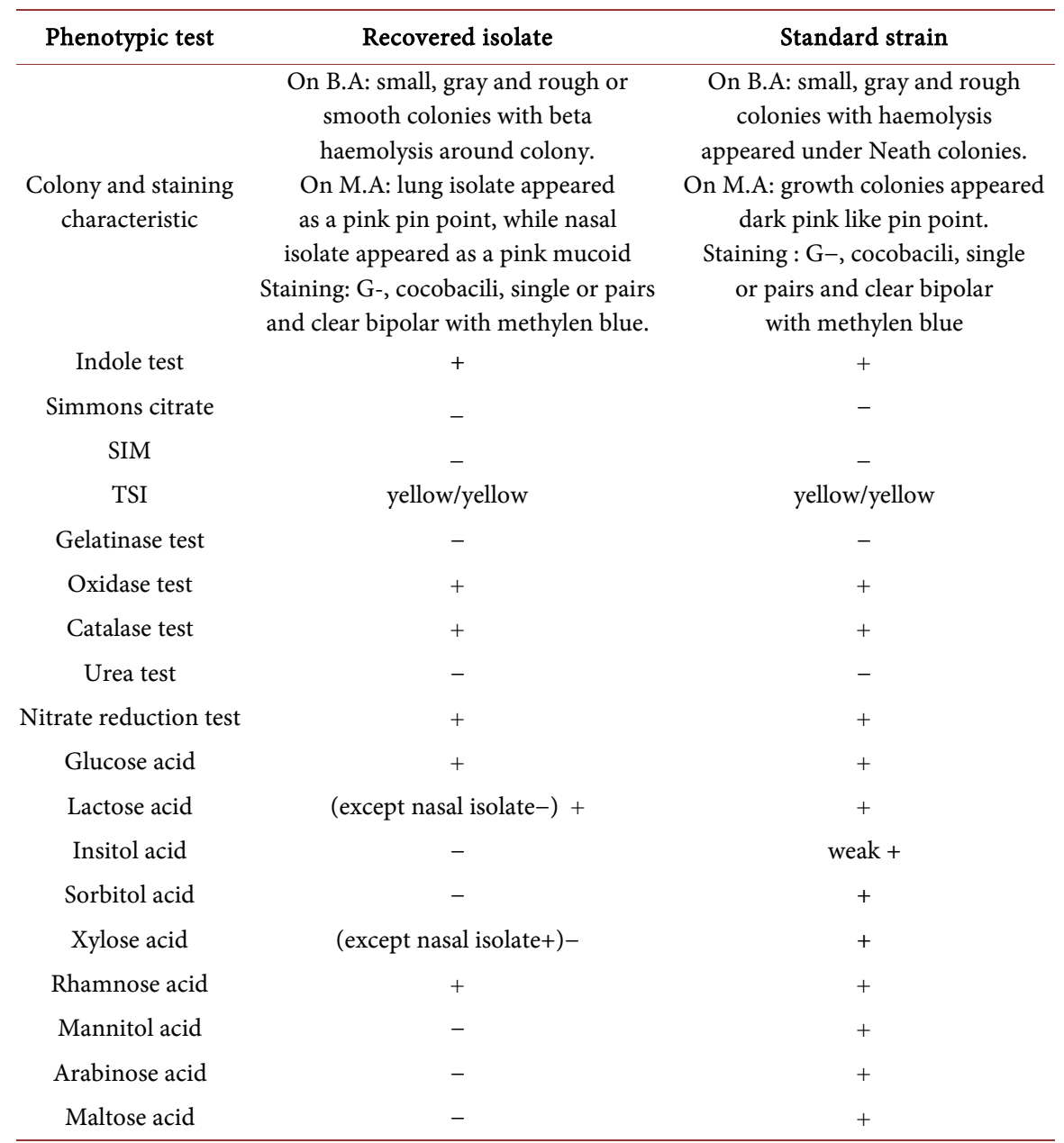


API20E results of the field isolates were appeared after $24 \mathrm{~h}$, the results were (ONPG+, ADH-, LDC-, ODC-, CIT-, H2S-, URE-, TDA-, IND-, VP-, GLE-, GLU+, MAN+, INO-, SOR-, RHA-, SAC+, MEL-, AMY+, ARA-). API20 kit was specific for Enterobacteriaceae not for Pasteurellaceae, another tests were added in order to get best results $(\mathrm{OX}+)$, the digit code of $M$. haemolytica was (1004125). it was identified by using API web. While standard strain of $M$. haemolytica appeared after $48 \mathrm{hr}$. the results were (ONPG-, ADH-, LDC-, ODC-, CIT-, H2S-, URE-, TDA-, IND-, VP-, GLE-, GLU-, MAN+, INO+, SOR+,RHA-, SAC+, MEL-, AMY-, ARA-) and confirmative test $(\mathrm{OX}+)$, the digit code was $(0000724))$. It was identified as a $M$. haemolytica by using API web.

Confirm identification for all strains of $M$. haemolytica by PCR analysis, Assay was performed, all isolates were tested to present $16 \mathrm{~s}$ rDNA and $12 \mathrm{~s}$ rRNA genes. Hence, all strains were positive for $16 \mathrm{~s}$ and $12 \mathrm{~s}$ primers, they showed a specific 304 bp and 270 band respectively on agarose gel, no amplification was observed in control negative (Figure 3 and Figure 4).

\section{Discussion}

Pneumonic pasteurellosis is one of the most economically important infectious diseases of goats, sheep and cattle with a wide prevalence throughout the continents [20] [21]. The negative results for isolation of $M$. haemolytica were observed from nasopharyngeal swabs during November 2015 to February 2016, while being isolated from slaughtered goats during March to April 2016. These results are in agreement with [22] who stated that calves may be negative for $M$. haemolytica on culture of nasal swabs. Also, pasteurellosis emerged as one of the major disease of animals adversely impacted by climate change [23]. Furthermore, they are in agreement with [24] who found that higher prevalence $M$. haemolytica was observed in spring and early summer. The negative results are

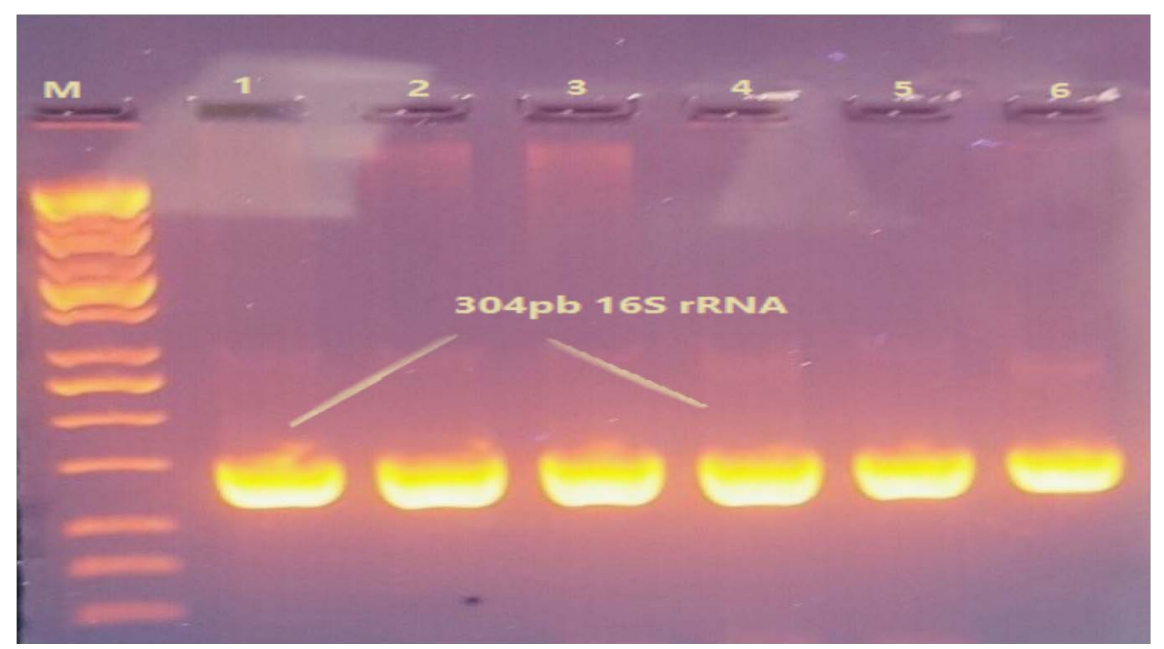

Figure 3. Agarose gel electrophoresis (1\%) of amplified 16 srRNA gene (304 bp ) of $M$. haemolytica, stained with ethidum bromide, Lane M: 100 bp ladder (1500 bp) Lanes 1 - 6: Five positive $M$. haemolytica isolates and the standard strain. 


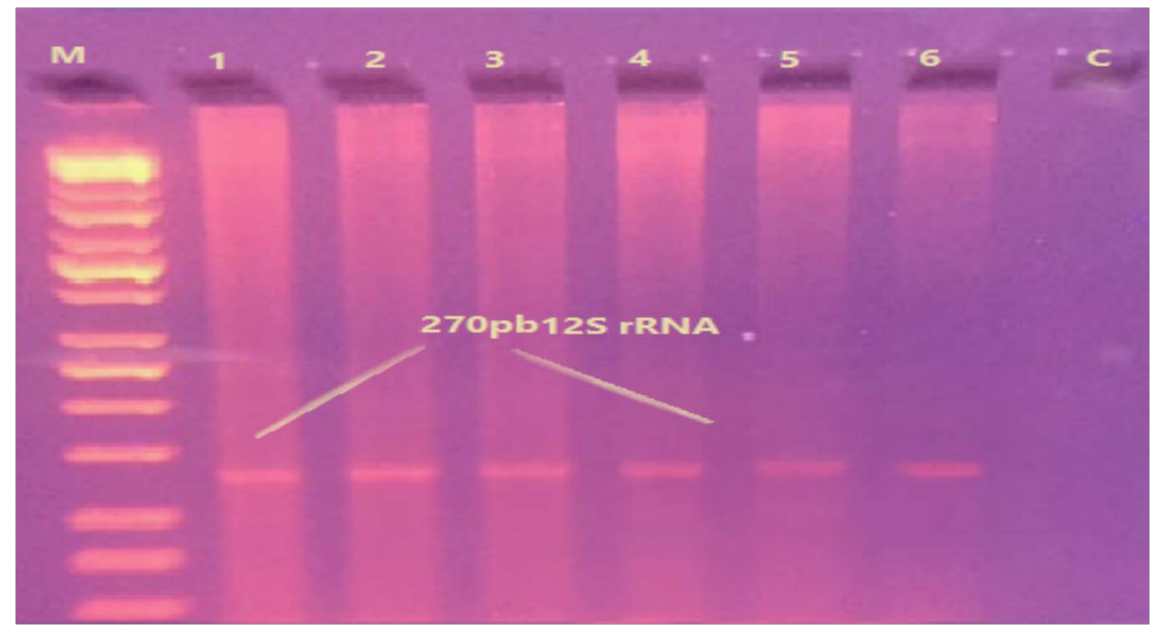

Figure 4. Agarose gel electrophoresis (1\%) of amplified 12 srRNA gene (270 bp ) of $M$. haemolytica, stained with ethidum bromide. Lane M: 100 bp ladder (1500 bp) Lanes 1 - 6: Five positive $M$. haemolytica isolates and standard, Lane c: negative control.

in agreement with [11] who pointed out for the negative isolation of M. haemolytica from nasopharyngeal swab of 3 healthy gazall, and with [25] who reported that $M$. haemolytica was not isolated from nasal swab of healthy animals, but $7(2.2 \%)$ isolates were obtained from diseased animal only. Also supported by [26] who reported that $M$. haemolytica is considered to be the major cause of bovine respiratory disease but it is rarely isolated from nasal swabs of healthy animals. The negative results for isolation of $M$. haemolytica from nasal swab are in disagreement with the isolation rate of $M$. haemolytica in the current study were $3(42.85 \%)$ and $2(40.00 \%)$ lung tissue specimens and nasal sinus mucus respectively from slaughtered goats. These results were higher and very convergent than 5/196 (2.55\%) from M. haemolytica isolated from pneumonic lung samples from goats and sheep [27]. Also higher than [28] who reported that 5 (3.37\%) isolates of M. haemolytica from goats and (15) isolate from cattle, buffalo and sheep from 148 samples of nasal swabs and lung tissue. Swabbing of the tonsils and nasal cavity of slaughtered sheep showed that $M$. haemolytica could be isolated from $95 \%$ of the tonsils and $64 \%$ of the nasopharyngeal swabs; the variation is likely to be caused by several factors including different isolation techniques, misidentification, and seasonal variation, [29]. The low isolation rate of $M$. haemolytica may be due delicate and very sensitive character of Mannheimia and these microorganisms not easily grow but need certain growth condition, these organisms flourished in a case in hydrolysate medium containing 15 individual amino acids, a mixtureof salts, vitamins, galactose and glucose [30]. The prevalence of $M$. haemolytica in previous investigation have shown a considerable variation, ranges between $8.9 \%$ and $96.2 \%$ of healthy sheep that carry these organisms in the nasal cavity [31]. The predisposing factors such as production stress in predominant climatic conditions of the region (hot weather, diurnal variations etc.) and changing weather patterns might have due to the stress established in the form of natural incidences of pneumonic pasteurellosis 
in sheep [32].

For decades, microbiologists have sought improved pathogen identification through the use of phenotypic methods, but they still rely on phenotypic identification. Phenotypic tests were used in current study for identification of $M$. haemolytica. All characterization results of phenotypic tests for M. haemolytica (field isolates and standard strain) are in agreement with [18] who reported that the $M$. haemolytica appeared as a large or small, gray and rough or smooth colonies appeared on blood agar with haemolysis which appeared after $24-48 \mathrm{hr}$ around or under neath the colonies, while it appeared as pink to red pinpoint colonies on MacConkey agar, except the nasal mucus isolate appeared as mucoid pink colonies on MacConkey agar, this result is closely agreement with [5] Also, the characterization of $M$. haemolytica isolates is in agreement with the findings reported by [33] that the isolate belong to $M$. haemolytica did not produce indole and grew on MacConkey agar.

All the 5 isolates and standard strain fermented glucose and rhamnose, the results are agreement with [34] Also, high variability for sugar fermentation was appeared between $M$. haemolytica isolates and standard strain, lactose fermentation observed by lung isolates and standard strain, of $M$. haemolytica, this result was similar to the finding reported by [35]. While, the nasal isolates were non lactose ferment, the results are in agreement with [5] While, the other carbohydrates fermentation of $M$. haemolytica were agreement with [5] [36] [37]. The variability observed in fermentation reactions of carbohydrates might be due to geographical variation of the isolates and use of chemotherapeutic agents as these factors will influence the enzyme profiles of microbes [38] or may be due to difference in the serotype of the isolates as serotype A ferments arabinose and serotype $\mathrm{T}$ ferments trehalose [18].

The five isolates and standard strain of $M$. haemolytica which positively identified by conventional biochemical's which were confirmed by API20E system. The results of API20E application for identification the field isolates were showed low discrimination for M. haemolytica with $18 \%$.The results were agreement with [39] that proved the lower reliability of this system for the identification of M. haemolytica. Although API only claims to place M. haemolytica into the right genus, it was only able to correctly place $20 \%$ of the isolates in that category. The API system depending on specific recorded code number in service computer, hence, there are deviates strains of $M$. haemolytica have been different characteristics from standard strain and may be not reported in code number of service computer. While, API20E, application for identification the Standard stain of M. haemolytica, gave good result for identification of $M$. haemolytica with $92.7 \%$, this result is in agreement with finding of [27] who successfully identified $M$. haemolytica by API20E. The five isolates and standard strain of M. haemolytica were positive for phenotypic and API20E tests, molecular identification was used to confirm identification.

All the 5 isolates and standard strain of $M$. haemolytica showed positive results for 16s rRNA gene and corresponds approximately size to $304 \mathrm{bp}$, this result 
is in agreement with finding of [16] were used the same primer which successively amplified to $304 \mathrm{bp}$ and to sequencing as $M$. haemolytica. In addition, when 12s rRNA gene was used, all isolates also showed positive results and corresponds to anticipate size $270 \mathrm{bp}$. This result was in agreement with [17] who detected $M$. haemolytica directly from lung tissues and from bacterial culture by used 12s rRNA gene. The results of this study showed that PCR as a valuable tool for rapid detection of $M$. haemolytica in clinical samples from goats. In addition, it offers the opportunity to perform large scale epidemiological studies regarding the role of $M$. haemolytica in clinical cases of pneumonia and other disease manifestations in sheep and other ruminants, thereby providing the basis for effective preventive strategies.

\section{References}

[1] Glimour, N.J.L. (1993) Pasteurellosis: The Disease in Production Animal. 43, 79-82.

[2] Acha, P.N. and Szyfres, B. (2003) Zoonoses and Communicable Disease, Common to Man and Animals. 3rd Edition, Pan American Health Organization, Washington DC, Scientific and Technical Publication No. 580, 1-2.

[3] Chamberland, R.R., Tekippe, M.E., Burnham, D.C. and Kennedy, J.D. (2013) Renal Abscess Caused by a Providencia stuartii Isolate Biochemically Misidentified as $\mathrm{Pa}$ teurella. Journal of Clinical Microbiology, 51, 2775-2777.

[4] Darmoul, M., Ben Nsir, A., Kilani, M. and Hattab, N.M. (2014) Hematogenous Pasteurella haemolytica Brain Abscess. Journal of Neurosciences in Rural Practice, 5 , 287-289. https://doi.org/10.4103/0976-3147.133608

[5] Punpanich, W. and Srijuntongsiri, S. (1998) Pasteurella haemolytica Septicemia in an Infant: A Case Report. The Journal of Infection in Developing Countries, 6, 584587.

[6] Mohamed, R.A. and Abdelsalam, E.B. (2008) A Review on Pneumonic Pasteurellosis (Respiratory Mannheimiosis) with Emphasis on Pathogenesis, Virulence Mechanisms and Predisposing Factors. Bulgarian Journal of Veterinary Medicine, 11, 139-160.

[7] Angen, O., Ahrens, P. and Bisgaard, M. (2002) Phenotypic and Genotypic Characterization of Mannheimia (Pasteurella) Haemolytica-Like Strains Isolated from Diseased Animals in Denmark. Veterinary Microbiology, 84, 103-114.

[8] Salman, A.J. (1989) Bacterial Etiology and Pathological Change of Upper and Lower Respiratory Tract in Sheep. A Thesis of Master, College of Veterinary Medicine, University of Baghdad, Baghdad.

[9] Al-Karagoll, A.J. (1992) Bacterial and Immunological Study on P. Haemolytica. A Thesis of Master, College of Veterinary Medicine, University of Baghdad, Baghdad.

[10] Al-Sultan, I.I. and Aitken, I.D. (1985) The Tonsillar Carriage of Pasteurella haemolytica in Lambs. Journal of Comparative Pathology, 951, 193-201.

[11] Ahmed, W.A. (1996) Pathological and Bacteriological Study of Respiratory Diseases in Mountain Goats, Gazelles and Dears in a Social Sector Field. A Thesis of Master, College of Veterinary Medicine, University of Baghdad, Baghdad.

[12] McPherson, M.J. and Moller, S.G. (2000) Polymerase Chain Reaction. BIOS Scientific Publishers Ltd., Oxford, 1-18.

[13] Townsend, K.M., Frost, A.J., Lee, C.W., Papadimitriou, J.M. and Dawkins, H.J.S. (1998) Development of PCR Assays for Species- and Type-Specific Identification of 
Pasteurella multocida Isolates. Journal of Clinical Microbiology, 36, 1096-1100.

[14] Corney, B.G., Diallo, I.S., Wright, L.L., Hewitson, G.R., De Jong, A.J., Burrell, P.C., Duffy, P.F., Stephens, C.P., Rodwell, B.J., Boyle, D.B. and Blackall, P.J. (2007) Pasteurella multocida Detection by 50 Taq Nuclease Assay: A New Tool for Use in Diagnosing Fowl Cholera. Journal of Microbiological Methods, 69, 376-380.

[15] Sabiel, Y.A., Musa, M.T. and Ann, V.Z. (2012) Identification of Mannhemia haemolytica and Pasteurella multocida by Polymerase Chain Reaction and Random Amplification of Polymorphic DNA. The Sudan Journal of Veterinary Research, 27, 55-59.

[16] Alexander, W.T., Cook, S.R., Yanke, L.J., Booker, W.C., Morley, S.P., Read, R.R., Gow, P.S. and McAllister, A.T. (2008) A Multiplex Polymerase Chain Reaction Assay for the Identification of Mannheimia haemolytica, Mannheimia glucosida and Mannheimia ruminalis. Veterinary Microbiology, 130, 165-175.

[17] Kumar, J., Dixit, K.S. and Kumar, R. (2015) Rapid Detection of Mannheimia haemolytica in Lung Tissues of Sheep and from Bacterial Culture. Veterinary World, 8, 1073-1077. https://doi.org/10.14202/vetworld.2015.1073-1077

[18] Quinn, P.J., Markey, B.K., Leonard, F.C., Hartigan, P., Fanning, S. and Fitz Patrick, E.S. (2011) Veterinary Microbiology and Microbial Disease. 2nd Edition, WileyBlackwell, Chichester.

[19] Donachie, W. (2008) The Disease of Sheep. 4th Edition, Blackwell, Oxford.

[20] Mohamed, R.A. and Abdelsalam, E.B. (2008) A Review on Pneumonic Pasteurellosis (Respiratory Mannheim Iosis) with Emphasis on Pathogenesis, Virulence Mechanisms and Predisposing Factors. Bulgarian Journal of Veterinary Medicine, 11, 3139-3160.

[21] Ozbey, G., Kilic, A., Ertas, H.B. and Muz, A. (2004) Random Amplified Polymorphic DNA (RAPD) Analysis of Pasteurella multocida and Mannheimia haemolytica Strains Isolated from Cattle, Sheep and Goats. Veterinary Medicine-Czech, 49, 6569.

[22] Frank, G.H., Briggs, R.E., Loan, R.W., Purdy, C.W. and Zehr, E.S. (1994) SerotypeSpecific Inhibition of Colonization of the Tonsils and Nasopharynx of Calves with Pasteurella Haemolytica Serotype A1 after Vaccination with the Organism. American Journal of Veterinary Research, 55, 1107-1110.

[23] Black, P. (2009) World Organization of Animal Health (OIE) Perspectives on the Impact of Climate Change on Animal Health. In: DTU Workshop on Climate Changes and Food Safety and Animal Health, 3rd Edition, Copenhagen.

[24] Gilmour, N.J.L. and Gilmour, J.S. (1989) Pasteurellosis of Sheep. In: Adlam, C. and Rutter, J.M., Eds., Pasteurella and Pasteurellosis, Academic Press, London, 223-262.

[25] El-Dokmak, M.M., Khalil, S.A. and Ebied, S.K.M. (2015) Genetic Diversity of Mannheimia Haemolytica Strains. Alexandria Journal of Veterinary Sciences, 47, 166-174.

[26] Abera, D., Sisay, T. and Birhanu, T. (2014) Isolation and Identification of Mannheimia and Pasteurella Species from Pneumonic and Apparently Healthy Cattle and Their Antibiogram Susceptibility Pattern in Bedelle District, Western Ethiopia. African Journal of Bacteriology Research, 6, 32-41.

[27] Hawari, A.D., Hassawi, D.S. and Sweiss, M. (2008) Isolation and Identification of Mannheimia haemolytica and Pasteurella multocida in Sheep and Goats Using Biochemical Tests and Random Amplified Polymorphic DNA (RAPD) Analysis. Journal of Biological Sciences, 8, 1251-1254. https://doi.org/10.3923/jbs.2008.1251.1254 
[28] Saed, M., Khaliel, S., Abd El-Mageed, A. and Khalifa, E. (2015) Genome Sequences of Gcp Gene of Mannheimia haemolytica Serotypes A1 and A2 Associated with Respiratory Manifestation of Ruminant in Egypt. Global Veterinaria, 14, 142-148.

[29] Gilmour, N.J.L., Thompson, D.A. and Fraser, J. (1974) The Recovery of Pasteurella haemolytica from the Tonsils of Adult Sheep. Research in Veterinary Science, 17, 413-414.

[30] Smith, G.R. and Philips, J.E. (1990) Pasteurella and Actinobacillus. In: Parker, M.T. and Duerden, B.I., Eds., Topley and Wilson's. Principles of Bacteriology, Virology and Immunology, Vol. 2, 8th Edition, BC Decker Inc., Hamilton, 383-399.

[31] Al-Tarazi, Y.H.M. and Dagnall, G.J.R. (1997) Nasal Carriage of Pasteurella haemolytica Serotypes by Sheep and Goats in Jordan. Tropical Animal Health and Production, 29, 177-179. https://doi.org/10.1007/BF02633019

[32] Kaoud, H., El-Dahshan, A.R., Zaki, M.M. and Nasr, S.A. (2010) Occurrence of Mannheimia haemolytica and Pasteurella trehalosi among Ruminants in Egypt. New York Science Journal, 3, 5.

[33] Tefera, G. and Smola, J. (2002) The Utility of Enterorapid 24 Kit for the Identification of P. Multocida and M. Haemolytica. Veterinary Medicine, 47, 99-103.

[34] Smith, J.E. (1974) Genus Pasteurella. In: Buchanan, R.E. and Gibbons, N.E., Eds., Bergey's Manual of Determinative Bacteriology, Williams and Wilkins Co., Baltimore, 370-373.

[35] MacFaddin, J.F. (2000) Biochemical Tests for Identification of Medical Bacteria. 3rd Edition, Lippincott Williams \& Wilkins, New York.

[36] Bisgaard, M. (1977) Incidence of Pasteurella haemolytica in the Respiratory Tract of Apparently Healthy Chickens and Chickens with Infectious Bronchitis. Characterization of 213 Strains. Avian Pathology, 6, 285-292. https://doi.org/10.1080/03079457708418238

[37] Angen, O., Mutters, R., Caugant, D.A, Olsen, J.E. and Bisgaard, M. (1999) Taxonomic Relationships of the Pasteurella haemolytica Complex as Evaluated by DNA-DNA Hybridizations and 16s Rrna Sequencing with Proposal of Mannheimia haemolytica gen. Nov., comb. Nov., Mannheimia granulomatis comb. Nov., Mannheimia glucosida sp. Nov., Mannheimia ruminalis sp. Nov. and Mannheimia varigena sp. Nov. International Journal of Systematic Bacteriology, 1, 67-86. https://doi.org/10.1099/00207713-49-1-67

[38] Rajini, R., Seshagiri, R.A., Dhanalakshmi, K. and Sarma, B.J.R. (1995) Studies on Avian Pasteurellosis in Andhra Pradesh. Indian Veterinary Journal, 72, 115-118.

[39] Collins, M.T, Weaver, N. and Ellis, R.P. (1981) Identification of Pasteurella multocida and Pasteurella haemolytica by API 20E, Minitek, and Oxi/Ferm Systems. Journal of Clinical Microbiology, 3, 433-437. 
Submit or recommend next manuscript to SCIRP and we will provide best service for you:

Accepting pre-submission inquiries through Email, Facebook, LinkedIn, Twitter, etc. A wide selection of journals (inclusive of 9 subjects, more than 200 journals)

Providing 24-hour high-quality service

User-friendly online submission system

Fair and swift peer-review system

Efficient typesetting and proofreading procedure

Display of the result of downloads and visits, as well as the number of cited articles Maximum dissemination of your research work

Submit your manuscript at: http://papersubmission.scirp.org/

Or contact aim@scirp.org 